International Conference on Renewable Energies and Power Quality (ICREPQ'11)

Las Palmas de Gran Canaria (Spain), 13th to 15th April, 2011

\title{
Modelling and Power Control of Wind Turbine Driving DFIG connected to the Utility Grid
}

\author{
Karim Belmokhtar, Mamadou Lamine Doumbia and Kodjo Agbossou \\ Department of Electrical and Computer Engineering \\ Université du Québec à Trois-Rivières \\ Trois-Rivières, G9A 5H7 Canada \\ Phone: +00181937650113912, \\ E-mail: karim.belmokhtar@uqtr.ca,mamadou.doumbia@uqtr.ca, kodjo.agbossou@uqtr.ca
}

\begin{abstract}
In this paper, the modelling and power transfer control of the variable speed wind energy system are presented. Firstly, a Maximum Power Point Tracking (MPPT) method is developed in order to maximize the energy generation of wind system based on doubly fed induction generator (DFIG). Then, the control of both Rotor Side Converter (RSC) and Grid Side Converter (GSC) is studied and the design of a multivariable selective filter is presented. Finally, simulation of a $850 \mathrm{~kW}$ doubly fed induction generator wind system was performed in the Matlab / Simulink / SimPowerSystems environment.
\end{abstract}

\section{Key words}

DFIG, Active Power, Reactive Power, Wind turbine, MPPT.

\section{Introduction}

Currently, wind energy has become a viable solution for energy production, in addition to other renewable energy sources. While most wind turbines are fixed speed, the number of variable speed wind turbines is increasing [1]. The DFIG with a vector control strategy delivers good performance and is commonly used in wind turbine industry [2]. There are many reasons for using a DFIG for a variable wind speed, such as reducing strain on mechanical parts, noise and the possibility for control active and reactive power [3].

The wind system using a DFIG and the back-to-back Pulse Width Modulation (PWM) converter which connects the rotor of the generator and the network has many advantages. One of them is the power converters used that are sized to pass a fraction of the total power of the system [4]-[5], thereby reducing losses in power electronic components.

The performance and output power do not depend only on the DFIG, but also the way the back-to-back converter is controlled. The back-to-back converter consists of two parts: the machine side converter called Rotor Side Converter (RSC) and the network side converter called Grid Side Converter (GSC). The RSC controls the active power and reactive power produced by the machine. The
GSC controls the DC bus voltage and power factor. In this study, a technique to control the two power converters is presented and the wind system dynamic performance is analyzed by simulations in Matlab / Simulink / SimPowerSystems. Firstly, the wind turbine is modeled then a MPPT technique for extracting the maximum power is presented. Subsequently, a model of the DFIG is derived in $d q$ reference frame. Finally, simulation results and their interpretation are provided.

\section{Modelling of the Wind Turbine}

The power extracted by a turbine depends on the power factor and it is given by the following equation [6] :

$$
P_{\text {extracted }}=\frac{1}{2} \cdot \rho \cdot S \cdot C_{p}(\lambda, \beta) \cdot v^{3}
$$

Where :

$\rho$ : mass density of air $\left[\mathrm{kg} / \mathrm{m}^{3}\right] ; v$ : speed of the wind $[\mathrm{m} / \mathrm{s}] ; \mathrm{S}$ : area swept by the blades $\left[\mathrm{m}^{2}\right] ; C_{p}$ : power coefficient; $\lambda$ : represents the ratio between the speed at the blade tip and wind speed; $\beta$ : is the blade angle.

The turbine is typically coupled to the generator shaft through a gearbox with a ratio $\mathrm{G}$, which is determined to maintain the generator speed within a desired range.

The wind turbine can produce only part of the power due to the kinetic energy of wind.

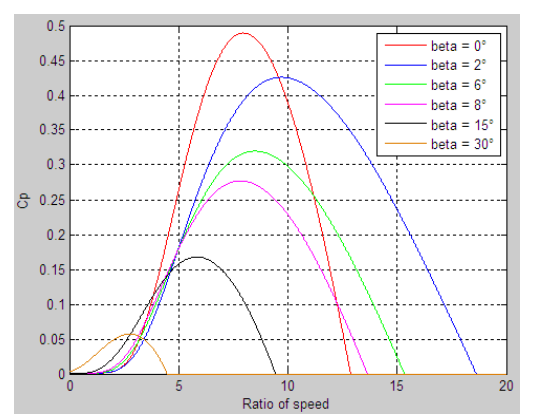

Figure -1- Power coefficient versus $\lambda$ and $\beta$ 
Performance or power coefficient $C_{p}$ depends on wind speed, the speed of the turbine and the pitch of the blades [7]. The power coefficient is intrinsic to the constitution of the wind turbine and depends on the profiles of the blades. The power coefficient can be modeled with a single equation that depends on the ratio $\lambda$ and the pitch of the blades $\beta$. This ratio, called also the tip speed ratio :

$$
\lambda=\frac{\Omega . R}{v}
$$

Where $\Omega$ is the speed of turbine, $R$ the blade radius and $v$ the wind velocity.

The power coefficient of the turbine is given by [8] :

$$
C p(\lambda, \beta)=c_{1} \cdot\left(c_{2} \cdot \frac{1}{A}-c_{3} \cdot \beta-c_{4}\right) \cdot e^{-c_{5} \cdot \frac{1}{A}}+c_{6} \cdot \lambda
$$

A typical relationship between the power coefficient of the turbine and the ratio $\lambda$ is shown in Figure 1.

Fixing the ratio $\lambda$ and the pitch blades $\beta$ to their optimum values, the wind system will provide optimum electrical power.

\section{Maximum Power Extraction}

To capture the maximum power from the wind, the speed of the wind turbine must be adjusted constantly. The optimum of the mechanical speed of the turbine is obtained when $\lambda=\lambda_{\text {opt }}=8$ and $\beta=0^{\circ}$.

The speed of the DFIG is used as a reference value for a Proportional-Integral (PI) regulator. This regulator determines the control set point which is the electromagnetic torque that should be applied to the machine to run the generator at its optimal speed. Then, the torque determined by the regulator is used as the reference torque of the turbine model as shown in Figure 2.

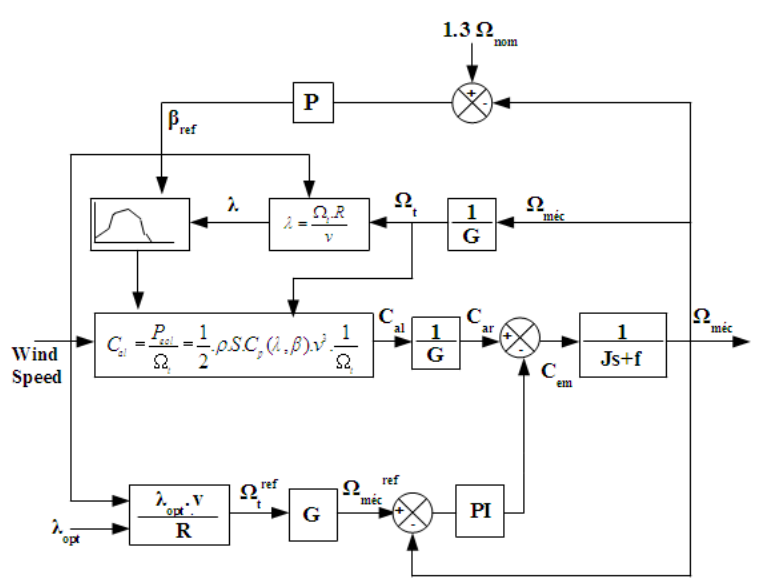

Figure -2-Scheme of the speed control of DFIG

The stall control method which is a passive technique is used. This allows to regulate the turbine speed when the generator speed exceeds $130 \%$ of its rated speed.

\section{Modelling of the DFIG}

The equations of the DFIG power in the reference frame $d q$ are given by [9]-[10] :

$$
\left\{\begin{array}{l}
v_{d s}=R_{s} i_{d s}+\frac{d}{d t} \phi_{d s}-\omega_{s} \phi_{q s} \\
v_{q s}=R_{s} i_{q s}+\frac{d}{d t} \phi_{q s}+\omega_{s} \phi_{d s} \\
v_{d r}=R_{r} i_{d r}+\frac{d}{d t} \phi_{d r}-\omega_{r} \phi_{q r} \\
v_{q r}=R_{r} i_{q r}+\frac{d}{d t} \phi_{q r}+\omega_{r} \phi_{d r}
\end{array}\right.
$$

With : $\omega_{r}=\omega_{s}-P . \Omega$

The stator and rotor flux are given as follows:

$$
\left\{\begin{array}{l}
\phi_{d s}=L_{s} i_{d s}+M i_{d r} \\
\phi_{q s}=L_{s} i_{q s}+M i_{q r} \\
\phi_{d r}=L_{r} i_{d r}+M i_{d s} \\
\phi_{q r}=L_{r} i_{q r}+M i_{q s}
\end{array}\right.
$$

Where $R_{s}, R_{r}, L_{s}, L_{r}$ and $M$ are respectively the resistances, the inductances of the stator and rotor winding, and the mutual inductance.

The expression of electromagnetic torque of the DFIG based on the fluxes and stator currents can be written as follows:

$$
T_{e m}=p\left(\phi_{d s} \cdot i_{q s}-\phi_{q s} \cdot i_{d s}\right)
$$

Where $p$ : the number of the pair of the poles

The active and reactive powers of the stator and the rotor of the DFIG are respectively given by :

$$
\left\{\begin{array}{l}
P_{s}=v_{d s} i_{d s}+v_{q s} i_{q s} \\
Q_{s}=v_{q s} i_{d s}-v_{d s} i_{q s} \\
P_{r}=v_{d r} i_{d r}+v_{q r} i_{q r} \\
Q_{r}=v_{q r} i_{d r}-v_{d r} i_{q r}
\end{array}\right.
$$

\section{Vector Control of DFIG}

The strategies of the control of the DFIG is based on two different approaches [11]:

- the closed loop control, where the frequency and voltage are considered variable (unstable grid).

- the open loop control, where the voltage and frequency are constant (stable grid).

In our study, the frequency and voltage are assumed constant.

One can see from the relation (6), the strong coupling between the fluxes and currents. This makes controlling of the DFIG particularly difficult. So, the vector control also called oriented flux control is used. The $d q$ reference frame is linked to the rotating field. The stator flux $\Phi_{s}$ is oriented along the axis $\mathrm{d}$. 


$$
\left\{\begin{array}{l}
\phi_{d s}=\Phi_{s} \\
\phi_{q s}=0
\end{array}\right.
$$

The expression of electromagnetic torque becomes :

$$
T_{e m}=-p \cdot \frac{M}{L_{s}} \phi_{d s} \cdot i_{q r}
$$

In the area of wind energy production, machines of medium and high power which are mainly used. Thus, the stator resistance was neglected. Assuming the stator flux constant, the stator voltage can be wrote as:

$$
\left\{\begin{array}{l}
v_{d s}=0 \\
v_{q s}=V s=\omega_{s} \Phi_{s}
\end{array}\right.
$$

According to equation (9), the electromagnetic torque of the DFIG can be controlled by controlling the q-axis rotor current $\left(i_{q r}\right)$.

Using the vector control, the active and reactive powers of the DFIG can be expressed as follows.

$$
\left\{\begin{array}{l}
P_{s}=-V_{s} \cdot \frac{M}{L_{s}} \cdot i_{q r} \\
Q_{s}=\frac{V_{s} \cdot \Phi_{s}}{L_{s}}-\frac{V_{s} \cdot M}{L_{s}} i_{d r} \\
P_{r}=g \cdot \frac{V_{s} \cdot M}{L_{s}} \cdot i_{q r} \\
Q_{r}=g \cdot \frac{V_{s} \cdot M}{L_{s}} \cdot i_{d r}
\end{array}\right.
$$

The total active and reactive output powers of the wind generator are given by :

$$
\begin{aligned}
& P_{t}=P_{s}+P_{r}=(s-1) \cdot V_{s} \cdot \frac{M}{L_{s}} i_{q r} \\
& Q_{t}=Q_{s}+Q_{r}=\frac{V_{s} \cdot \Phi_{s}}{L_{s}}+(s-1) \cdot V_{s} \cdot \frac{M}{L_{s}} i_{d r}
\end{aligned}
$$

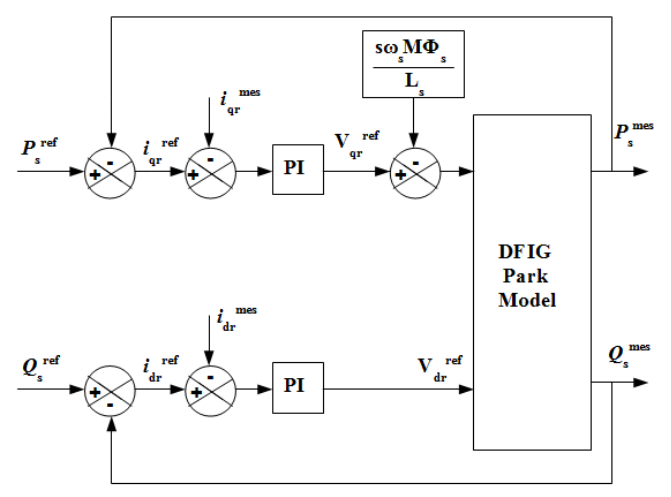

Figure -3- Power control of the DFIG

For a unity power factor operation of the system, the total reactive power ( $Q_{t}=0$ ) is maintained to zero.
The advantage of this control strategy is the possibility to use additional power regulators in the case where the grid frequency is unstable (Figure 3).

\section{Control of RSC and GSC}

\section{A. Rotor Side Converter Control}

The control principle of the rotor side converter (RSC) allows the control of active and reactive power and the extraction of maximum wind power (Figure 4).

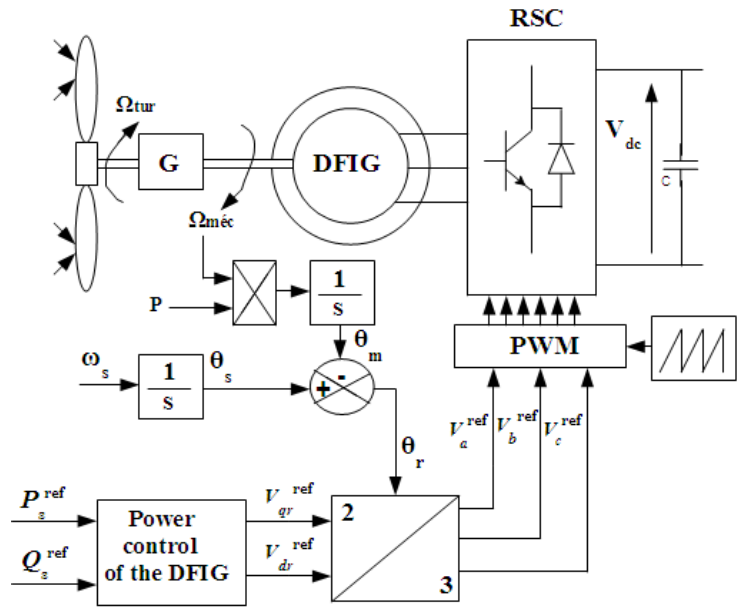

Figure -4- Control principle of the RSC

\section{B. Grid Side Converter Control}

The Grid Side Converter (GSC) ensures the regulation of the DC bus voltage and adjusts the power factor on the grid side. The GSC is a bidirectional converter which operates as a rectifier when the slip (s) is positive (subsynchronous mode) and as an inverter when the slip is negative (supersynchronous mode).

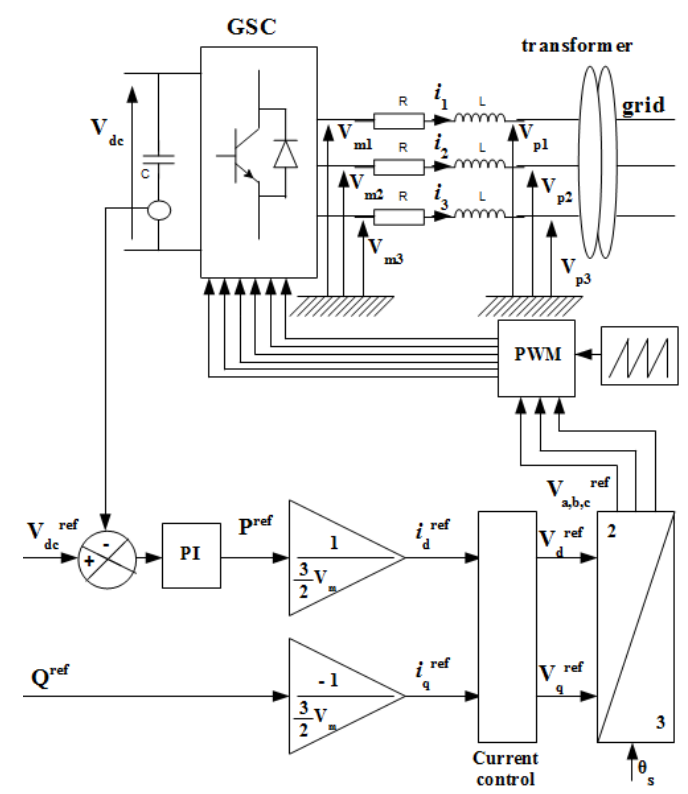

Figure -5- GSC converter control scheme

The active and reactive powers at the grid side are written respectively as follows [11]: 


$$
\left\{\begin{array}{l}
P=\frac{3}{2} V_{m} \cdot i_{d} \\
Q=-\frac{3}{2} V_{m} \cdot i_{q}
\end{array}\right.
$$

Where $V_{m}$ is the amplitude of phase voltage.

The control of the DC bus voltage allows to obtain the reference value of the active power. Also, the power factor can be adjusted by the reference reactive power (Figure $5)$.

\section{Multivariable Filter Design}

Figure 6 shows the reference voltages for the control of the grid side converter. To improve the harmonic content of this voltage, a multivariate filter is proposed. This selective filter has the advantage of having a zero phase shift at the cut-off pulse. It allows extracting only the fundamental waves of the reference voltages, without causing a lagging phase [12]. So, the output signal remains in phase with the input signal.

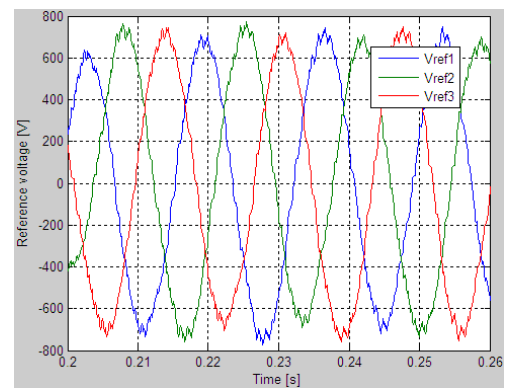

Figure -6- Reference voltages before filtering

The filter extracts the fundamental of three voltage $V_{a}^{\text {ref }}$, $V_{b}^{r e f}$ et $V_{c}^{\text {ref }}$. In the $\alpha \beta$ frame, the output voltages $\hat{V}_{\alpha}$ and $\hat{V}_{\beta}$ of the filter are expressed in terms of input voltages $V_{\alpha}$ and $V_{\beta}$ as shown in the following expressions :

$$
\begin{aligned}
& \hat{V}_{\alpha}(s)=\frac{K}{s}\left[V_{\alpha}(s)-\hat{V}_{\alpha}(s)\right]-\frac{\omega_{c}}{s} \hat{V}_{\beta}(s) \\
& \hat{V}_{\beta}(s)=\frac{K}{s}\left[V_{\beta}(s)-\hat{V}_{\beta}(s)\right]-\frac{\omega_{c}}{s} \hat{V}_{\alpha}(s)
\end{aligned}
$$

The above equations are used to obtain the overall scheme of the multivariable selective filter (Figure 7).

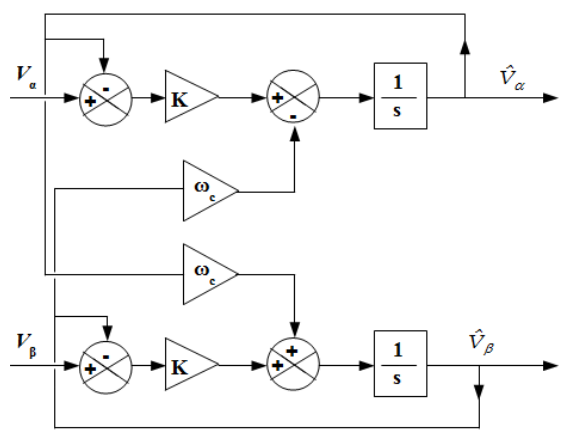

Figure -7- Multivariable selective filter scheme
The waveform of the reference voltages after using a multivariable filter is shown in Figure 8.

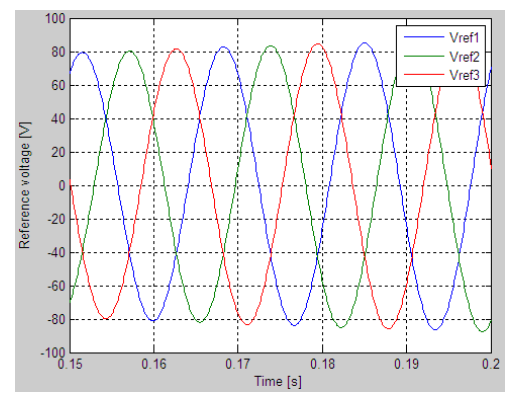

Figure -8- Reference voltages after filtering

\section{Simulation Results}

The structure of the DFIG wind energy system is illustrated in Figure 9. The DFIG connected directly to the grid through the stator, and its speed is controlled via a back-to-back PWM converter.

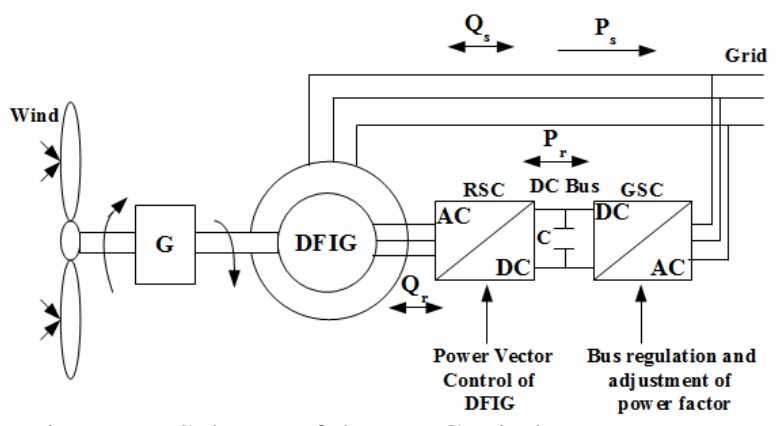

Figure -9- Scheme of the DFIG wind energy system

The parameters of the DFIG are given in Appendix. A random wind profile is applied to the system (Figure 10).

Figure 11 shows the zoom of the waveform of the stator voltage and current. We can see that the current and voltage are in phase opposition. This confirms that the DFIG is sending active power to the grid.

Figure 12 shows the generator slip. Figures 13 and 14 illustrate respectively the stator active power and reactive power. We can see the robustness of the power control of the DFIG.

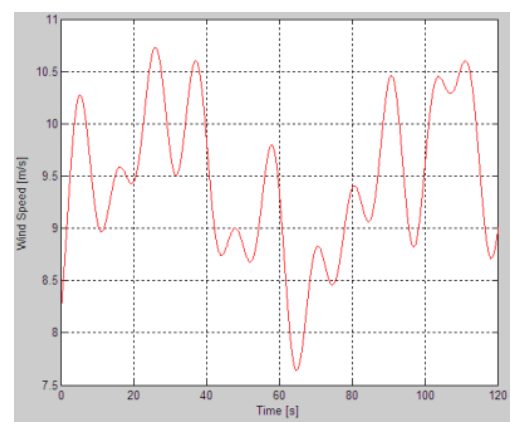

Figure -10- Random wind speed profile

Figures 15 and 16 respectively represent the rotor active power and reactive power rotor. For $\mathrm{s}>0$ (subsycnhronous mode), the DFIG absorbs active power and for $\mathrm{s}<0$ (supersycnhronous mode), the rotor active power is supplied by the generator. Figure 17 shows voltage and current of the GSC. Figure 18 shows the 
voltage and current of the grid. We note that the current and voltage are in phase opposition, meaning that energy is sent from DFIG to the grid.

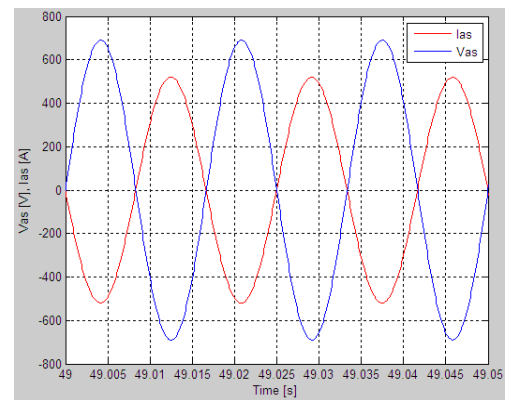

Figure -11- Stator voltage and current

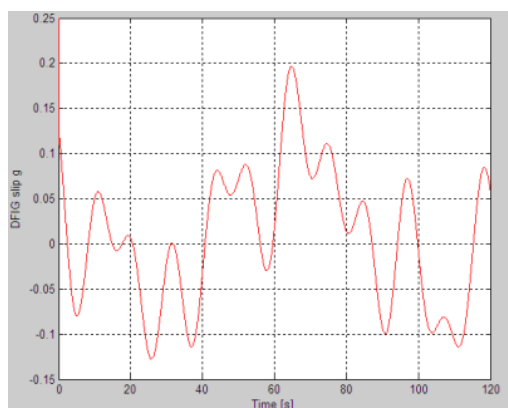

Figure -12- DFIG slip

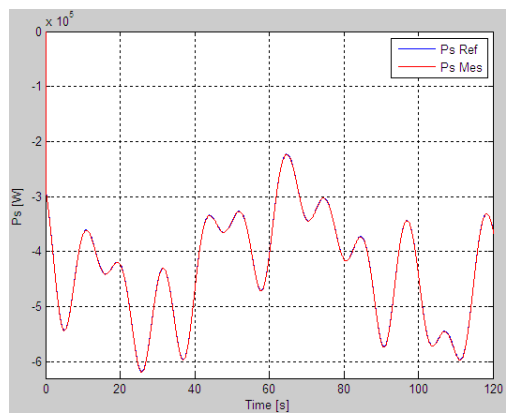

Figure -13- Stator active power

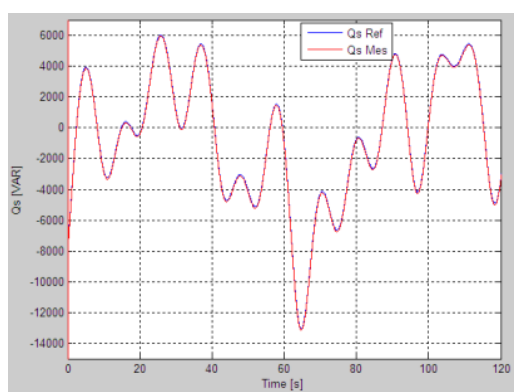

Figure -14- Stator reactive power

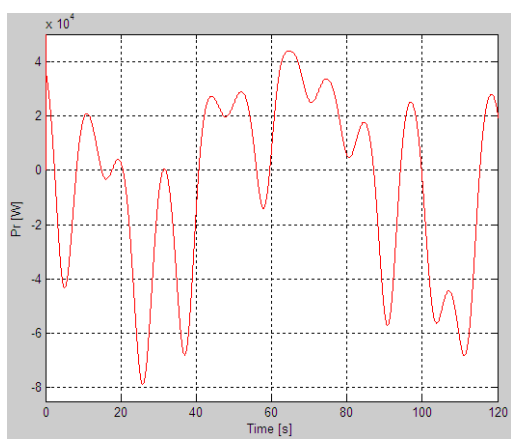

Figure -15- Rotor active power

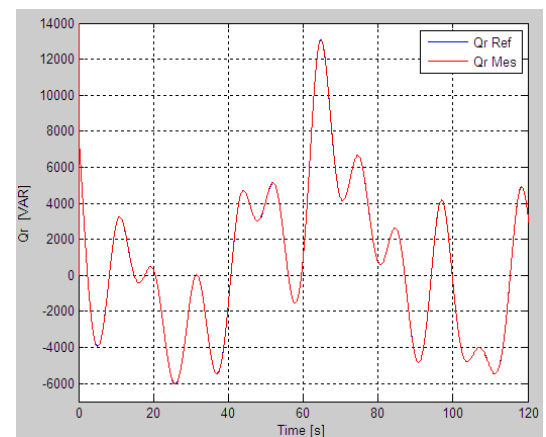

Figure -16- Rotor reactive power

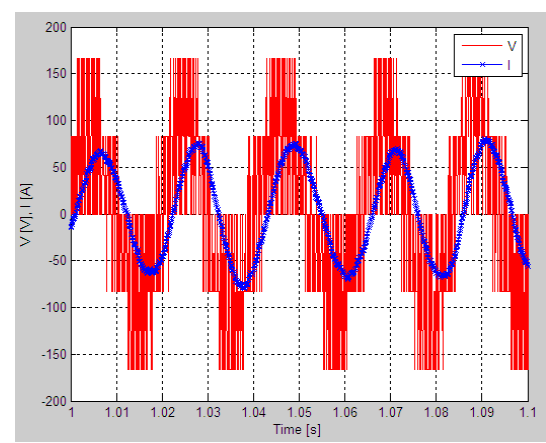

Figure -17- Voltage and current of the GSC

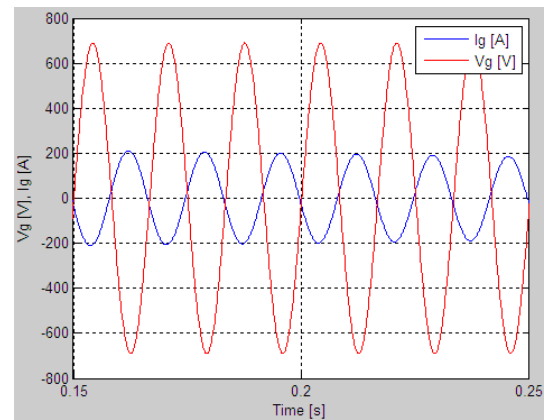

Figure -18- Voltage and current to grid

\section{Conclusion}

This article has been devoted to modeling, simulation and analysis of a wind turbine operating at variable speed. Stable operation of the wind system was obtained with the application of the vector control. The overall operation of the wind turbine system and its control were illustrated by the responses to active and reactive powers control. The DFIG operates in two quadrants. Subsynchronous operation for positive slips and a Supersynchronous operation for negative slips. The generator supplied active power to the grid regardless to the mode of operation. The wind system has been modeled and tested with a $850 \mathrm{~kW}$ generator. Simulation results show that the proposed wind system is feasible and has many benefits.

\section{Acknowledgement}

This work has been supported by the LTE Hydro-Québec and the Natural Sciences and Engineering Research Council of Canada. 


\section{References}

[1] T. Ackermann and Soder, L. «An Overview of Wind Energy-Status $2002 »$. Renewable and Sustainable Energy Reviews 6(1-2) 2002, pp. 67-127.

[2] S. Li and T. A. Haskew, «Analysis of Decoupled d-q Vector Control in DFIG Back-to-Back PWM Comverter». PES General Meetig June 2007, pp. 17.

[3] T. Burton, D. Sharpe, N. Jenkins and E. Bossanyi, « Wind Energy Handbook », John Wiley\&Sons, Ltd, 2001

[4] W. L. Kling and J. G. Slootweg, « Wind Turbines as Power Plants » in Proceeding of the IEEE/Cigré workshop on Wind Power and the impacts on Power Systems June 2002, 17-18, Oslo, Norway.

[5] L. Xu and C. Wei, «Torque and Reactive Power Control of a Doubly Fed Induction Machine by Position Sensorless Scheme». IEEE Trans, Industry Application, May/June 1995, vol. 31, no. 3, pp. 636642.

[6] C. Eisenhut, F. Krug, C. Schram and B. Klöckl, «Wind-Turbine Model for System Simulations Near Cut-in Wind Speed». IEEE Trans, on Energy Conversion, June 2007, vol. 22, no. 2, pp. 414-420.

[7] L. Chang, «Systèmes de conversion de l'énergie éolienne». IEEE Canadian Review, Summer 2002, pp. 1-5.

[8] S. Heier, « Grid Integration of Wind Energy, Conversion Systems », New-York: John Wiley \& Sons Ltd (1998).

[9] K. Ghedamsi, «Contribution à la modélisation et la commande d'un convertisseur direct de fréquence.
Application à la conduite de la machine asynchrone », $\mathrm{PhD}$ Thesis, ENP Algiers (Algéria), 2008

[10] S. E. Ben Elghali, «Modélisation et Commande d'une hydrolienne Equipée d'une génératrice Asynchrone Double Alimentation », JGGE'08, 1617 Décembre 2008, Lyon (France)

[11] X. Yao, C. Yi, D. Ying, J. Guo and L. Yang, « The grid-side PWM Converter of the Wind Power Generation System Based on Fuzzy Sliding Mode Control », Advanced Intelligent Mechatronics, IEEE 2008, Xian (Chine), pp. 973-978.

[12] A. Boyette, Contrôle-commande d'un générateur asynchrone à double alimentation avec système de stockage pour la production éolienne, $\mathrm{PhD}$ Thesis, Nancy, France, 2006.

\section{Appendix}

DFIG parameters

\begin{tabular}{|l|c|}
\hline Rated power & $850 \mathrm{~kW}$ \\
\hline Voltage rated & $690 \mathrm{~V}$ \\
\hline Stator resistor per phase & $0.016 \Omega$ \\
\hline Rotor resistor per phase & $0.0125 \Omega$ \\
\hline Inductance of the stator winding & $6.85 \mathrm{mH}$ \\
\hline Mutual inductance & $6.78 \mathrm{mH}$ \\
\hline Inductance of the stator winding & $6.90 \mathrm{mH}$ \\
\hline Number of pole pairs & 4 \\
\hline Inertia & $30 \mathrm{kg.m}^{2}$ \\
\hline
\end{tabular}

